\title{
Pandora: un grupo en donde la curiosidad mantiene viva la esperanza
}

Volumen 6 N. ${ }^{\circ} 47$ julio - diciembre de 2019

ISSN: 0122-4328

ISSN-E: 2619-6069 pp. $49-62$

\author{
Pandora: A Group \\ where Curiosity \\ Keeps Hope Alive
}

\author{
Pandora: um grupo \\ onde a curiosidade \\ mantém viva a \\ esperança
}

\author{
Jairo Nelson Pulido Gómez* \\ Rossmajer Guataquira López \\ Sindy Paola Joya Cruz"* \\ Martha Cecilia Clavijo Riveros \\ Viviana Uni Muñoz \\ Rubén Felipe Morales Camargo
}

Fecha de recepción: 30-09-18

Fecha de aprobación: 07-12-19

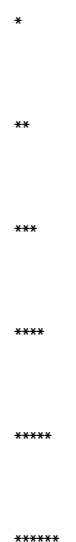
org/10.17227/nyn.vol6.num47-8471 Riveros, M., Muñoz, V. y Morales Camargo, R. (2019). Pandora: un grupo en donde la curiosidad mantiene viva la esperanza. Nodos y Nudos, 6(47). https://doi.
Docente de Matemáticas, Colegio Campestre Monteverde IED. Localidad Chapinero (Bogotá, Colombia). jnpulido@educacionbogota.edu.co

Docente de Matemáticas, Colegio Anibal Fernández de Soto. Localidad de Suba (Bogotá, Colombia). rossmajerg@gmail.com

Docente de Matemáticas, Colegio Isabel II IED. Localidad de Kennedy (Bogotá, Colombia). sindy.joya@gmail.com

Pulido Gómez, J., Guataquira López, R., Joya Cruz, S., Clavijo (i) $\$$ 


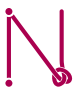

Volumen 6 N. ${ }^{\circ} 47$ julio - diciembre de 2019 ISSN: 0122-4328 ISSN-E: 2619-6069 pp. $49-62$

\section{RESUMEN}

En el presente artículo de reflexión, se abarca un conjunto de ideas asociadas a la conformación de un grupo de docentes de matemáticas en la ciudad de Bogotá (Colombia), quienes están en la búsqueda del encanto de esta área del conocimiento y cuyas discusiones se centran en la diversidad de saberes que circulan en el aula de clase, el papel de la motivación en el aprendizaje, el rol de la curiosidad en la adquisición del conocimiento y el deseo por aprender. En un primer momento se narran los encuentros iniciales, las motivaciones del grupo para reunirse, los temas de discusión, los objetos de estudio, las perspectivas compartidas y las divergentes, las experiencias. Luego aparece un problema aparentemente sencillo "la suma de números consecutivos", que no solo se analiza al interior del grupo, sino se lleva a diferentes contextos. Todo esto generó que cada quién viviera experiencias que se analizarian de una forma más amplia. En el artículo se describen, según el espacio donde se desarrolló, aproximaciones desde el trabajo en el aula, trayectorias del grupo, formas de interacción y algunas proyecciones. El documento finaliza con una reflexión sobre la incidencia de los docentes, los estudiantes, el sistema educativo, los imaginarios sociales, las interacciones, las propuestas tradicionales y las innovadoras; pero tal vez el más fuerte, la descripción del trabajo en redes y colectivos y el potencial que tiene en proyectos de investigación en cualquier nivel.

Palabras clave: curiosidad; matemáticas escolares; narrativas; experiencias de indagación y experimentación; perspectiva fractal

\section{ABSTRACT}

This reflection article covers a set of ideas associated with the formation of a group of mathematics teachers in the city of Bogotá (Colombia), who are in search of the charm of this area of knowledge and whose discussions focus in the diversity of knowledge that circulates in the classroom, the role of motivation in learning, the role of curiosity in acquiring knowledge and the desire to learn. At first, the meetings, the motivations of the group to meet, the topics of discussion, the objects of study, the shared and divergent perspectives, and the experiences are narrated. Then appears an apparently simple problem "the sum of consecutive numbers", which is not only analyzed within the group, but is taken to different contexts. All this generated that each one lived experiences that would be analyzed in a broader way. The article describes, according to the space where it was developed, approaches from the work in the classroom, trajectories of the group, forms of interaction and some projections. The document ends with a reflection on the incidence of teachers, students, the educational system, social imagery, interactions, traditional and innovative proposals; but perhaps the strongest is the description of networking and collective work and the potential it has in research projects at any level.

Keywords: curiosity; school mathematics; narratives; experiences of inquiry and experimentation; fractal perspective

\section{RESUMO}

Este artigo de reflexão aborda um conjunto de idéias associadas à formação de um grupo de professores de matemática na cidade de Bogotá (Colômbia), que buscam o encanto dessa área do conhecimento e cujas discussões se concentram na diversidade de conhecimentos que circula na sala de aula, o papel da motivação na aprendizagem, o papel da curiosidade na aquisição de conhecimentos e o desejo de aprender. No início, são narradas as primeiras reuniões, as motivações do grupo para se reunir, os tópicos de discussão, os objetos de estudo, as perspectivas compartilhadas e divergentes, as experiências. Em seguida, aparece um problema aparentemente simples "a soma de números consecutivos", que não é apenas analisado dentro do grupo, mas é levado para diferentes contextos. Tudo isso gerou que cada um vivesse experiências que seriam analisadas de forma mais ampla. 0 artigo descreve, de acordo com o espaço em que foi desenvolvido, abordagens a partir do trabalho em sala de aula, trajetórias do grupo, formas de interação e algumas projeções. 0 documento termina com uma reflexão sobre a incidência de professores, alunos, sistema educacional, imagens sociais, interações, propostas tradicionais e inovadoras; mas talvez o mais forte, a descrição do trabalho em rede e coletivo e o potencial que ele tem em projetos de pesquisa em qualquer nível.

Palavras-chave: curiosidade; matemática escolar; narrativas; experiências de investigação e experimentação; perspectiva fractal 
Recuerda mirar a las estrellas y no tus pies. Intenta dar sentido a lo que ves y pregúntate por lo que hace al universo existir. Sé curioso. Aunque la vida puede parecer dificil, siempre hay algo que puedes hacer y tener éxito.

Lo importante es que no te rindas.

Stephen HaWking

Cuenta la historia que Pandora, víctima de la curiosidad, abrió la caja en la que estaban contenidos todos los bienes y los males, dejando ir todo lo que en ella había, excepto la esperanza. De manera similar tuvo origen nuestro grupo de docentes de matemáticas denominado Pandora, quienes en marzo de 2018 decidimos abrir la caja -aquel espacio en el cual trabajamos- para propiciar discusiones en torno a la clase de matemáticas y a las tensiones, aciertos, dificultades y posibilidades que alli se presentan.

La curiosidad fue nuestro punto de partida y la motivación para reunirnos, discutir y encontrar alternativas de mejora para aquello que estaba fuera de la caja: mensajes desesperanzadores, predisposición de maestros y niños respecto a las matemáticas, ideas de futuro pesimistas, porvenires rotos, fuertes críticas a la labor docente, ideas en torno a las matemáticas como algo neutral, y algunas concepciones, creencias y narrativas de los sujetos de la clase configuradas en afirmaciones en el interior de las familias y en los medios de comunicación, quienes señalan que el aprendizaje de las matemáticas es exclusivamente para aquellas personas con capacidades excepcionales.

De las reuniones y conversaciones que tuvieron lugar en Pandora, surgió la visualización de posibilidades futuras de cambio y la configuración de mecanismos de intervención y participación, que propiciaran en las narrativas del profesor y los estudiantes, el gusto, curiosidad e interés por aprender matemáticas, por descubrir en ellas aspectos nuevos y atrayentes. Todo esto motivaría no solo el estar en el aula, sino también ampliar el espacio de aprendizaje a la discusión con el otro, reconocer posturas distintas a la propia, buscar la utilidad de lo que se decide aprender e identificar en sí mismos talentos, habilidades y gustos que se desconocian o que no habian aflorado en una clase tradicional.
De igual modo, empezaron a surgir preguntas respecto a cómo iniciar el trabajo en las instituciones y qué responder mediante este. Es preciso señalar que a pesar de que la motivación intrínseca que nos movía era fuerte y nos hacía desear cambios, lograr la transformación de las prácticas y gestar clases de matemáticas que aportaran al desarrollo de habilidades en los estudiantes y les permitieran tomar decisiones adecuadas en su vida cotidiana, no era una tarea fácil de abordar.

Así, llevamos a cabo reuniones periódicas para compartir posturas, inquietudes, miedos y experiencias que se evidenciaban continuamente en las clases; y también, para realizar indagaciones que dieran luces acerca de nuevas teorías y caminos, que permitieran modificar/reforzar/mejorar nuestras prácticas y los procesos de aprendizaje de nuestros estudiantes, dotar de esperanza y compartir aquello que hasta ahora identificamos en nuestras realidades.

Para tal efecto, comenzamos a hacer un análisis sistémico de la realidad, a partir del cual consideramos las situaciones y los sujetos que intervienen en el proceso de enseñanza y aprendizaje de las matemáticas, desde una mirada compleja, fractal y caótica (Morin, 1999); de igual manera, una mirada en la que cada pequeña situación, elemento o sujeto forma parte de un conjunto más grande, el cual, a su vez, vuelve a pertenecer a un nuevo conjunto, este de otro y asi sucesivamente, en una correspondencia que se puede iterar múltiples veces (Mandelbrot, 2004).

Es decir, debido a estas características de la realidad, los análisis no podían ser concebidos con una perspectiva simple, pues estamos inmersos en un mundo complejo, conformado por un entramado de relaciones, sujetos, creencias, vivencias y expectativas.

Pero ¿cómo ver y analizar nuestras experiencias? y más aún, ¿cómo hacer visible lo que no se puede ver a simple vista? Para acercarnos a estas preguntas, consideramos inicialmente que la experiencia es el mecanismo que permite observar con mayor sensibilidad, en especial si el ejercicio de experiencia/reflexión se lleva a cabo a manera de bucle, volviendo a aquello que se observa una y otra vez. A partir de esta idea, nos aproximamos al trabajo de un personaje ícono en la educación en Colombia: el profesor 
Dino Segura (1999), quien con su trayectoria, experiencia y crítica del sistema tradicional de educación ha mostrado una forma alternativa de ver la educación. Él, por medio de asesorias y discusiones, nos condujo a problematizar nuestra mirada de la educación, la propia práctica y sugirió algunas situaciones problema y lecturas que nos posibilitaron develar un poco más lo que estábamos emprendiendo.

De ese modo, en aras de profundizar las comprensiones que tenemos de lo que corresponde a lo educativo, autores como: (Hanson, 1971) para estudiar "la perspectiva y la experiencia"; Peirce (1901, 1902, 1903, citado por Henao, 2007) quien esboza "el pensamiento abductivo", (Poincaré, 1890) quien habla de "la recurrencia", (Mandelbrot, 2004) creador de "La perspectiva fractal", (Bateson y Bateson, 1989) para aclarar "Los tipos de aprendizaje", (Maturana y Varela, 1997) autores que trabajan "sistemas autorregulados", (Morin 1999, 2000) quien expone la perspectiva de la complejidad, entre otros. Teorías que fueron discutidas en el interior de Pandora y de las cuales surgen varias ideas de trabajo para con los estudiantes, no en términos de enseñanza, sino en la manera de leer el mundo, los seres que lo habitan y las interacciones que alli tienen lugar.

En coherencia con esa forma de percibir el mundo, consideramos que las clases podian tener un desarrollo diferente si nosotros, junto con nuestros estudiantes, interactuamos en torno a un objetivo común, reflexionando, cuestionando y acercándonos a nuevos conocimientos. Aqui nuestra esperanza estaba depositada en que lo desarrollado en la clase tuviera la potencialidad para motivar a nuestros estudiantes a construir conocimiento, nutrir curiosidades y compartir las vivencias y los aprendizajes a otros.

Esta iniciativa implicó pensar en una cadena de formulación de la actividad, preguntas en forma de bucle, un plan de trabajo con roles a desempeñar, para que de manera constante se generaran discusiones y surgieran argumentos, posicionamientos y resultados que reanudaran el ciclo.

La primera idea que se puso en práctica en nuestras aulas estuvo relacionada con un problema, en el que se les propuso a los estudiantes: "Encontrar dos números consecutivos que al sumarse den como resultado 120", esto con el propósito de identificar formas de razonamiento que sirvieran como elementos para dialogar en torno al desarrollo, ventajas y desventajas de este tipo de trabajo en el aula.

\section{Algunos resultados}

En la resolución del problema relatado en el apartado anterior, encontramos que los estudiantes usan la información presentada y la relacionan con datos de sus experiencias para llegar a establecer una respuesta a la pregunta. Esto explica por qué aquellos que han sido tradicionalmente rotulados como buenos en matemáticas, rechazan de inmediato la posibilidad de encontrar tales números, bajo la premisa de que un número par no puede generarse de la suma de un par y un impar, lo que hace imposible entonces resolver el ejercicio. Al mismo tiempo, surgieron otras respuestas, enmarcadas en la idea de que ser consecutivo no implica solamente que los números tengan una diferencia de uno, sino que los números pertenezcan a una misma serie o cumplan con una característica que los agrupa; redefiniendo algunas nociones.

Precisamente ese tipo de respuestas abrieron otras voces en la clase, las de aquellos que tradicionalmente no tienen buen desempeño, porque lejos de considerar ideas y concepciones matemáticas trabajadas, incluyeron otras que facilitarian una solución el ejercicio planteado, por ejemplo: "Los números son consecutivos si su diferencia es 1 , entonces 59,5 y 60,5 son consecutivos y su suma es 120"; otra idea expuesta por los estudiantes indicaba que "en la lista de números 57,$5 ; 58,5 ; 59,5 ; 60,5 ; 61,5$ y 62,5 hay tres formas de sumar $120 ; 57,5+62,5 ; 58,5+61,5$ y $59,5+60,5 "$ ", de modo similar con números con otras características, por ejemplo los múltiplos de 10 mayores o iguales a 10 y menores o iguales a 110, con excepción del 60.

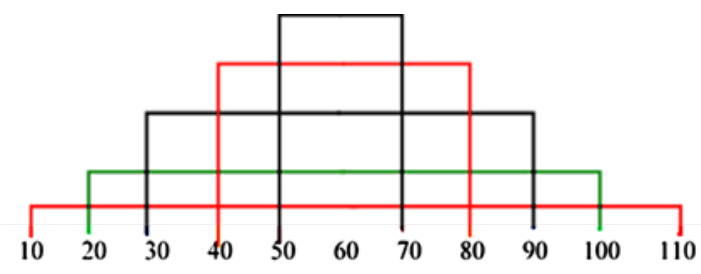

Figura 1. Reconstrucción de tipos de respuesta de estudiantes de grado séptimo.

Fuente: elaboración propia. 
En la figura 1 se puede observar una representación procedimental de algunos estudiantes, quienes encuentran una relación entre parejas de números que suman 120, como por ejemplo el 10 y el 110, el 20 y el 100, el 30 y el 90, etc. Acto que incitó a debatir el significado de consecutivo y los contextos en donde puede habitar. Para este proceso se hizo un análisis de razonamiento inferencial, similar al que propone Ludlow (1998).

La participación de los estudiantes fue notable y nos condujo a discusiones en torno a los siguientes cuestionamientos: ¿En dónde está el encanto de las matemáticas? ¿Qué moviliza a un estudiante en el área de matemáticas para trabajar en una actividad? ¿Qué lo mueve a trabajar un tema, dentro y fuera de la clase? ¿Qué es lo realmente importante que se debe aprender en matemáticas? Las preguntas empezaron a tener eco en cada miembro del equipo de trabajo y nos llevó al planteamiento de algunas hipótesis:

»Existe un conjunto de saberes que los estudiantes vinculan en las clases que son en ocasiones más significativos para ellos y para el desarrollo de la clase, que aquellos que los maestros y el sistema de educación ha predeterminado en los planes de estudio y en los currículos sugeridos.

» Cambiar la dinámica de la clase, el tipo de preguntas que le hacemos a los estudiantes y formular preguntas inquietantes/descabelladas de las cuales no otorgamos respuestas, puede favorecer la emergencia de respuestas creativas que no solo están sujetas a lo que se está tratando en la clase, sino a las experiencias que los estudiantes han adquirido en otros espacios fuera del aula.

" Ante la imposibilidad de resolver un problema, los estudiantes utilizan argumentos para modificar las condiciones iniciales de la situación y así proponer formas de solución creativas, lo cual resulta una actividad educativa muy valiosa, pues promueve en la clase la construcción colectiva de conocimiento, la justificación y validación de argumentos y abre espacios para realización de contextos de matematización.
» Los estudiantes hacen grandes descubrimientos y adquieren habilidades de resolución de problemas y situaciones, cuando se permite que discutan, argumenten y pongan en consideración sus ideas y las de otros; siempre y cuando el ambiente de clase posibilite la participación, debate, contraste de ideas y la búsqueda de soluciones en conjunto.

» En la actualidad, una gran parte de la comunidad científica y matemática está comenzando a aceptar que el mundo es caótico y que, por tanto, el determinismo no siempre puede dar cuenta de lo que sucede y está por suceder en el mundo, en las personas, en la naturaleza, en la economía, en la vida. Por esa razón, es necesario incursionar, comprender y trabajar aquellas teorías que dan cuenta de la complejidad y de la conformación fractal del mundo.

»El conocimiento es una construcción social y una red compleja de relaciones e interconexiones; en consecuencia, el aprendizaje no debe darse de manera individual, segmentada ni aislada, sino que debe ser el producto de las interacciones entre los sujetos, los sujetos/el contexto, los sujetos/ el saber y del sujeto consigo mismo, pues así se está en la capacidad de ampliar las miradas que se tienen y se comprenden los temas, circunstancias y objetos con mayor profundidad.

Frente a este panorama ampliamos la exploración con discursos didácticos, legales, psicológicos, matemáticos o políticos en la literatura educativa que nos permitiera comprender lo que estaba sucediendo en el aula en comparación a lo que habiamos logrado con el ejercicio de los números consecutivos.

Particularmente, en la búsqueda de comprender las razones por las cuales en la sociedad y en los medios de comunicación hay una imagen desacreditada tanto de los profesores de matemáticas, como de las matemáticas en sí mismas y de los jóvenes que van a la escuela, realizamos algunas indagaciones teóricas que nos ayudaran vislumbrar este panorama. En este recorrido encontramos, por ejemplo, según los planteamientos de Foucault (1967, 1998, citado por 
Ovejero y Pastor, 2001), que la escuela se ha venido configurando, así como otros escenarios, para fabricar individuos sumisos, normalizados y dóciles. En cuanto al ejercicio del poder que valida un saber y con ello una visión de mundo, evidenciamos una conflictividad entre: subjetividad y prospecto de la sociedad; algunos grupos sociales pequeños y la hegemonía; contexto cotidiano y contexto escolar; entre otros.

Concluimos, entonces, que quizás esa preocupación por atender a las demandas del sistema educativo y la sociedad configura en el aula una tensión entre los sujetos que estamos involucrados reduciendo las posibilidades e iniciativas de unos y otros; situación que se complejiza si consideramos que, con frecuencia, el conocimiento se muestra como una verdad frente a la cual los sujetos deben ceder, asimilar y normalizar, y al minimizar su posibilidad de acción, los estudiantes se encontrarán en un espacio en el cual se les induce a negar su naturaleza social, creativa y propositiva.

A partir de las hipótesis creadas, fruto del problema inicial ya descrito, tomó mayor fuerza la idea de esperanza, manifiesta en Pandora, en su curiosidad y en las posibilidades que quedaron abiertas en el momento mismo de abrir la caja. En ese sentido, se empezaron a realizar las clases en la búsqueda por favorecer la exploración, indagación y creatividad con estudiantes en cada una de las instituciones donde laboramos, tratando de lograr dinámicas de trabajo provechosas como las alcanzadas con la actividad de los números consecutivos.

\section{De la esperanza al trabajo dentro y fuera de la caja}

Anteriormente se esbozó de manera somera la conformación del grupo Pandora y unos primeros hallazgos; a continuación, narraremos algunas particularidades de lo que ha ocurrido en las aulas y de cómo se da la relación entre docentes y estudiantes en torno a las matemáticas.

\section{Experiencia de indagación: alterando el infinito}

En una de las instituciones, mientras los estudiantes de grado octavo resolvían un problema de análisis de conjuntos, la docente decidió preguntarles qué números conforman el conjunto de los pares, cuáles el conjunto de los impares y cuáles el conjunto de los naturales; para resolver la situación usaron diferentes diagramas de Venn y colocaron en ellos algunos de los números que pertenecen a cada conjunto.

Cuando la docente indagó respecto a la cardinalidad de cada colección, los estudiantes contestaron: "Infinito"; y la docente, buscando incentivar su curiosidad -consciente de aspectos que corresponden a la cardinalidad del conjunto y expectante por lo que pudiera generarse al problematizar la idea señalada por ellos-, se quedó mirando el tablero y preguntó en voz alta: "¿No les parece raro que el conjunto de los números naturales sea igual de grande al de los números pares?, esto teniendo en cuenta que el conjunto de los números pares es un subconjunto de los naturales". Los estudiantes miraron al tablero con asombro y cuando esperaban que la docente explicara algo al respecto, la clase se terminó.

Esa pregunta intencionada fue el detonante y el inicio de un grupo estudiantil de indagación acerca del infinito en el Colegio Aníbal Fernández de Soto (jornada de la tarde), conformado por estudiantes de grado octavo que, desde mayo de 2018, se reunian con la docente en mención, en las horas del descanso, para socializar, discutir y analizar información que consultaban en casa, sobre el infinito.

Dicho grupo inició con 7 estudiantes del curso 802 $y$, posteriormente, se unieron otras personas de este mismo curso y de 801. Asi se ha conformado un grupo de alrededor de 13 estudiantes hasta el momento, pues, aunque algunos han desertado, constantemente se unen nuevos integrantes que llegan atraidos por los resultados y narrativas, que emiten en la clase (y fuera de ella), los que pertenecen a este colectivo.

Precisamente esas narrativas han empezado a configurar la curiosidad en unos y otros, y con esta, el gusto por las matemáticas; igualmente han propiciado en los estudiantes el descubrimiento de nuevos talentos en sí mismos, desarrollo de habilidades comunicativas y sociales, interés por la lectura, participación en discusiones intelectuales y ponencias interinstitucionales, un mejor aprovechamiento del tiempo libre y el despertar de su gusto por la investigación, entre otros aspectos. 
"Yo creo que sí se puede..."

Siguiendo la estructura del planteamiento de los números consecutivos como parte de los problemas que exigen argumentos para su resolución y condiciones que los limitan, se sugieren dos ejercicios para indagar sobre la creatividad y las estrategias de solución de los estudiantes: El Spot It y los tableros mágicos. La estructura de estos problemas se ha desarrollado en algunas investigaciones de la Escuela Pedagógica Experimental como la de Malagón (1995), en una de las categorías se encuentran los problemas irresolubles.

\section{Spot It}

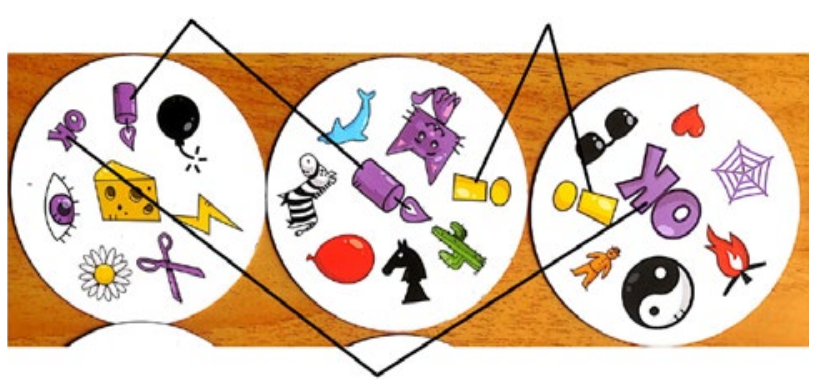

Figura 2. Juego Spot It

Fuente: Elaboración propia.

Comenzó como un juego de cartas, el cual tiene la característica principal, que existe siempre solo una imagen en común entre cualquier par de cartas que uno escoja. ¿Cómo es esto posible?, ¿se puede determinar la cantidad de cartas si se tienen 8 imágenes y hay 4 imágenes por carta?, entre otros.

Esta serie de preguntas junto con otras que emergieron durante el ejercicio, permitieron captar la atención de los estudiantes frente al reto de crear un juego similar, aunque para la construcción se cambiaron las imágenes por números, mientras se estudiaba a fondo la manera como estaba hecho.

Luego de hacer esfuerzos para crear las cartas, los estudiantes perciben que al restringir algunas condiciones, como la de utilizar 8 imágenes en total, no se puede crear el juego con características similares.
Tableros mágicos

Basado en el problema tablero de ajedrez mutilado propuesto por el filósofo analítico Max Black en su libro "Critical Thinking" (Pensamiento Crítico) (1946).
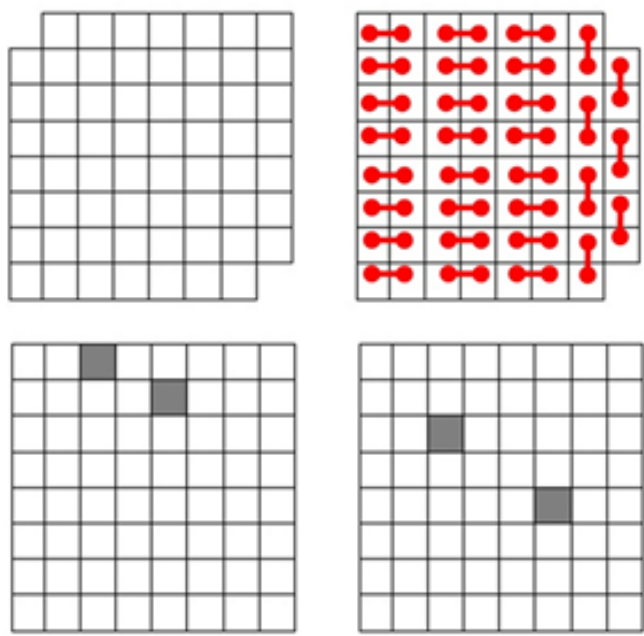

Figura 3. Reelaboración tableros presentados Problema tableros mágicos.

Fuente: elaboración propia.

Consiste en trabajar en tableros de ajedrez (dimensiones de $8 \times 8$ cuadros) luego de quitar dos cuadros, el objetivo es completar el tablero sobreponiendo segmentos que unan dos cuadros, ya sea vertical y horizontal, nunca diagonal, tal como lo muestra la figura 3 en el segundo tablero de izquierda a derecha, los tableros 1, 3 y 4 muestran algunas de las variaciones de los dos cuadros que se pueden quitar. La situación aparentemente sencilla toma un grado de dificultad, pues algunos tableros no se pueden completar con las condiciones dadas.

En ambas situaciones es importante reconocer que:

»El reto fue el gancho que mantuvo a los estudiantes comprometidos con el problema.

»En algunos casos la capacidad de ser persistente desaparece al verse atascado en el problema.

» La confianza es lo que permite agrado por la situación, es decir ver que es fácil de manipular y de resolver, inicialmente. 
"Sin dar indicaciones puntuales, los estudiantes buscan diferentes estrategias y solución, y una gran cantidad de intentos fallidos.

"Existe dificultad para utilizar los argumentos adecuados para probar las distintas hipótesis que aparecen.

» Manejar representaciones gráficas por los estudiantes resulta más sencillo que utilizar otro tipo de representación.

"Se deben pensar diferentes estrategias para mantener el entusiasmo de los estudiantes.

" La esperanza de "yo creo que sí se puede..." permite sacarle provecho a la situación.

\section{Exploración en torno a la conjetura de Collatz: “iY siempre volvemos al uno!"}

Otra experiencia se generó en el Colegio CEDID San Pablo, dentro de un programa de jornada extendida al cual asisten libremente estudiantes de distintos grados y cursos, buscando en parte mejorar sus conocimientos en matemáticas, así como ocupar su tiempo libre, permanecer menos tiempo en la casa, entre otros. Las discusiones en este grupo de estudiantes se dieron a partir de un ejercicio, manifiesto en la siguiente instrucción: "Elige un número, si es par divídelo en 2 pero si es impar multiplicalo por 3 y súmale 1, continúa el proceso hasta que lo consideres".

La instrucción es precisa, sin embargo, es un problema de iteración que corresponde a la conjetura de Collatz, la cual plantea que luego de hacer procesos iterativos siempre alcanza el 1, es un problema matemático que hasta la fecha no tiene demostración. Esta situación además de generar en los estudiantes motivación por estudiar las matemáticas, por redescubrir su encanto, por hacer uso de los conocimientos previos y generar otros, por pensar y hablar usando el lenguaje matemático, entre otros, les permitió formular y refutar ideas frente a las secuencias de números que emergieron gracias a distintas estrategias.

Así mismo, lo desarrollado posibilitó en los estudiantes incluir otros elementos, como sus motivaciones, incertidumbres y logros, en las narrativas que construyeron luego de abordar el problema. Por ejemplo, Andrés, un estudiante que abordó el ejercicio manifestó:

Mi mayor motivación era probar que el uno no era el límite y que de alguna forma $u$ otras encontraría algo distinto al final de cada secuencia, sin embargo, los intentos fallaron, pero fue muy divertido. Además de practicar [...] [con los] números, es una buena estrategia para poder pasar el tiempo. Hubo veces donde me rendí por la pereza [...] pero recordaba el objetivo por el cual lo hacia, encontrar un número diferente al final de la secuencia. Eso significa que cada vez que nosotros queramos hacer algo tenemos que tener constancia en aquello porque si lo hacemos pocas veces y lo dejamos no tendrá el mismo efecto de hacerlo seguido y luchar por tus objetivos, pudo empezar como un proyecto bastante pequeño, pero engrandeció mi vida con conocimiento.

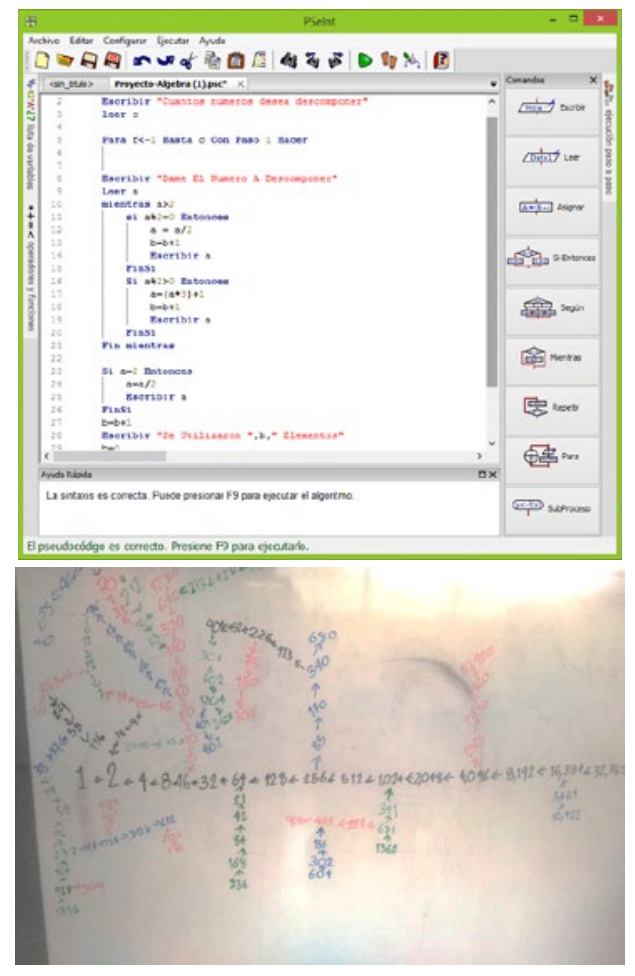

Figura 4. Producciones colegio CEDID San Pablo

Fuente: elaboración propia.

De esta narrativa puede entonces destacarse que al igual que en Pandora, lo que mantiene al estudiante desarrollando el ejercicio e indagando diferentes posibilidades es precisamente la curiosidad y el deseo por mostrar alguna elaboración que de algún modo contradiga la conjetura de Collatz. 


\section{Los cohetes en el espacio de las matemáticas}

En otra latitud, correspondiente al Colegio La Concepción IED, el docente ha empezado a privilegiar las voces de los estudiantes con baja participación, visibilizando sus elaboraciones y renunciando a la idea de las respuestas únicas y predeterminadas, dando paso entonces a la posibilidad de errar y buscar nuevas alternativas, así como de encontrar respuestas múltiples a una misma tarea.

En esta institución se ha diversificado el trabajo con los estudiantes de grados séptimo y noveno, en busca de la reflexión e indagación, por parte de estudiantes, sobre fenómenos asociados al viaje de cohetes y proyectiles, generando en ellos el interés de lograr mejores desempeños en el lanzamiento, verificando y contrastando datos tomados no solo por ellos, sino también por otras personas en diferentes del mundo.

El abordaje de la actividad matemática en esta institución ha variado significativamente, pues ha pasado de un modelo tradicional, enmarcado en el plan de área, a otro más abierto, en el que los conceptos, fórmulas y modelos son indagados, compartidos y verificados por los estudiantes, quienes ahora tienen un rol activo en la clase, cuyas principales caracteristicas son la indagación y la puesta en común de los hallazgos individuales, asi como la confrontación, debate y discusión de lo hallado, lo conocido y lo que falta por explorar.

\section{Entre-tejiendo con las matemáticas}

De modo similar a lo ocurrido en las experiencias descritas brevemente en este documento, el trabajo que ha tenido lugar en el Colegio Isabel II IED, ha tenido contrastes, variaciones y posibilidades que avivan la esperanza. Alli, la docente partió desde una invitación que llegó al colegio para participar en el Sexto Encuentro Juvenil de Matemáticas, durante 2017. Bajo este pretexto, se presentó una transversalidad de áreas académicas, en la que los estudiantes diseñaron cometas en la clase de matemáticas y, posteriormente, estrategias para poder calcular la altura a la que cada una podría llegar al elevarla, teniendo en cuenta diferentes variables que pudieran incidir en la situación, las construyeron en la clase de artes y redactaron escritos y pósteres de la experiencia en la clase de español. Esta participación, sacó a los estudiantes del aula de clase y les permitió conocer la experiencia de otros; asi quedaron abiertas muchas preguntas relacionadas con la forma de hacer matemáticas que fueran más reales para las vivencias de cada uno.

Durante 2018 y con el inicio de Pandora, los actuales estudiantes de grado undécimo de la institución propusieron variados escenarios en los que se pudiera involucrar las matemáticas de una manera diferente. En ese sentido, la clase se ha orientado al desarrollo de habilidades de pensamiento que requieren condiciones de flexibilidad y apertura que estimulen la interacción, la participación individual y grupal, la expresión libre, la discusión de ideas y la posibilidad de aprender tanto de los errores como de los aciertos.

En este momento los estudiantes han recurrido a las matemáticas para el diseño de imágenes que representan fractales, el uso de tejidos para la construcción de manillas y cuadros, el origami para representar figuras en movimientos tridimensionales $y$ el diseño de estrategias para ganar juegos de rol. Así mismo, han participado en diferentes eventos académicos distritales en los que pueden experimentar y compartir con expertos en educación matemática.

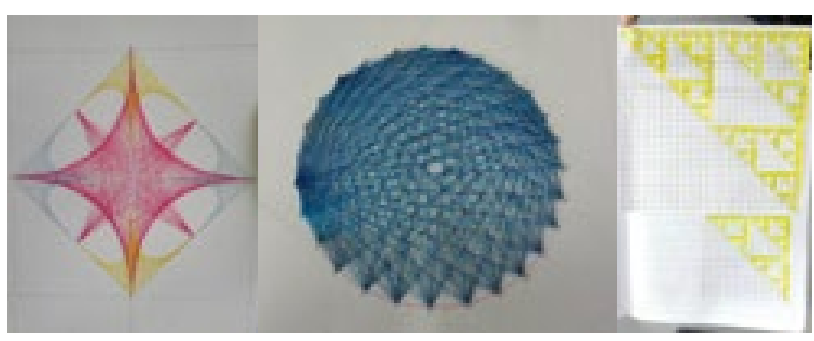

Figura 5. Producciones colegio Isabel II IED

Fuente: elaboración propia

\section{Geometría en burbujas}

En el colegio San Bernardino iED de la localidad de Bosa, los estudiantes de grado undécimo se encontraron durante el tercer periodo realizando una actividad de cinefórum para la clase de matemáticas; analizaron el capitulo 2 de la serie The Code, donde se explican matemáticamente algunas situaciones de la naturaleza, 
de alli salió la idea de replicar la construcción de polígonos y sólidos platónicos con burbujas.
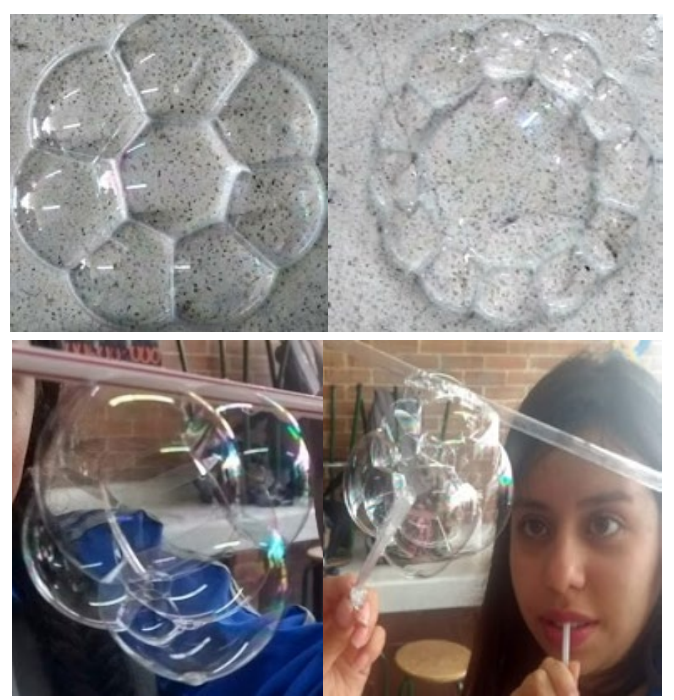

Figura 6. Producciones Colegio San Bernardino IED

Fuente: elaboración propia

La actividad, aunque inició como un juego, ha llevado a los estudiantes a preguntarse, entre otras: ¿Qué son los polígonos? ¿Qué son los sólidos? ¿Por qué al juntar las burbujas o pompas de jabón se forman estos polígonos y sólidos? Sin embargo, aun como docentes, al usar estas actividades como excusa para abordar objetos matemáticos, queda la duda sobre la rigurosidad de las matemáticas que con ellas se alcanza. Al respecto, los estudiantes respondieron:

El trabajar con burbujas en clase de matemáticas es una forma alternativa y didáctica para ayudar en el aprendizaje de la geometría y hacerlo más interesante para el estudiante. Además a través de prácticas didácticas se adquiere conocimientos en temas que ayudarán al estudiante en toda su vida académica como el método de investigación.

Tal vez para muchos maestros y padres suene fuera de lugar el enseñar sólidos platónicos con burbujas, pero no es así, ya que el realizar esta práctica conlleva más esfuerzo del esperado, porque se requiere de aplicar todo un proceso investigativo acerca de factores ambientales, factores fisicoquimicos y los materiales aptos para la elaboración de burbujas. (Estudiantes Curso $1101 \mathrm{JT}$ )

Aunque el propósito de la clase es trabajar sólidos platónicos, claramente la actividad activa una red de conceptos, no solo de matemáticas sino de otras áreas, que terminan contribuyendo a un aprendizaje significativo para los estudiantes. En consecuencia, esta experiencia motiva al docente a seguir pensando en situaciones que contextualicen los conceptos matemáticos, como dispositivos que mejoran la concentración y participación de todos sus alumnos en la clase.

De nuevo en esta experiencia, como en las relatadas en páginas anteriores, ingresan a escena aquellos estudiantes que se consideran malos para matemáticas o que no les gusta trabajar en ella, mostrando sus habilidades físicas al manipular las burbujas y conseguir rápidamente la construcción de polígonos y sólidos, lograr reconocimiento por algún tipo de liderazgo al ayudar a sus compañeros a cumplir con el objetivo de la clase.

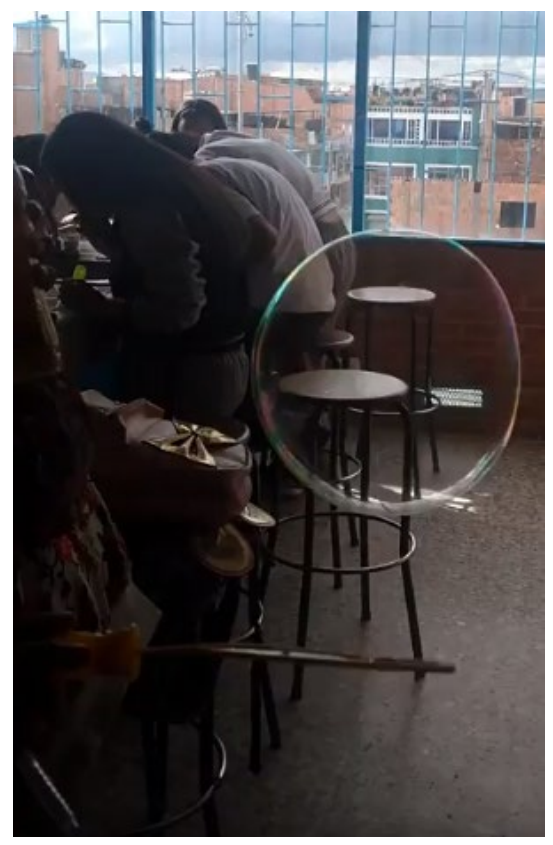

Figura 7. Trabajo con pompas de jabón en clase Colegio San Bernardino IED

Fuente: elaboración propia 


\section{Ya para terminar}

En el presente documento narramos nuestra historia como un grupo de maestros que volvimos a descubrir, junto a nuestros estudiantes, el encanto de las matemáticas; con el fin de resaltar la relevancia de las redes y colectivos de maestros para la generación de espacios distintos para las futuras generaciones en el campo de la investigación.

Esta travesía, y convencidos que la conformación de redes y los espacios de discusión contribuyen a un ambiente de investigación y de cultura académica, nos llevó a organizar un encuentro estudiantil, en el que los jóvenes que han participado en dichas vivencias socialicen, discutan, analicen sus experiencias, los resultados matemáticos y personales alcanzados; esto, como una manera de crear colectividad también entre los alumnos, además que la misma experiencia de todos los participantes del grupo han dejado que la construcción de conocimiento entre pares es mucho más significativo.

Con respecto a lo que nos proponemos, el grupo Pandora a corto plazo analizará las diversas experiencias de forma sistémica, para encontrar similitudes, diferencias, caracteristicas, incidencias, entre muchos más atributos que pueden orientarse según las siguientes preguntas: ¿Qué tienen en común esas experiencias educativas? ¿Cómo caracterizar los resultados obtenidos? ¿Qué ha hecho que se consigan los resultados alcanzados? ¿Cómo se pueden mejorar las experiencias? ¿Por qué nuestras clases cotidianas distaban de las experiencias que se han tenido? Por lo pronto, tenemos la certeza, la necesidad, de repensar la enseñanza de las matemáticas y la manera de abordarse en el aula de clase, pero no solo desde la teoría, sino desde la práctica misma, donde se puede transformar los sentimientos de desidia o desinterés de nuestros estudiantes para con la clase de matemáticas.

Con lo anterior, se anidan intereses de investigación para Pandora, como:

» Generar colectivos de estudiantes a través de un tema común: esto se evidenció en el establecimiento de nuevas amistades a partir de la empatía que sintieron entre alumnos en el abordaje del ejercicio y en la proliferación de charlas en distintos espacios.
"Consolidar un registro tangible de cómo el desarrollo de estas actividades reivindica a las matemáticas con aquellos estudiantes que durante varios años de su vida escolar han cargado con el rótulo de ser malos para las matemáticas.

» Propiciar cambios en el ambiente de la clase, permitiendo a los estudiantes reconocer que el desempeño relativo en la asignatura no supone mejores desempeños en todas las cuestiones asociadas a ella, y por consiguiente que el conocimiento que circula en la clase no surge solo de unos cuantos, con habilidades especiales, sino que puede provenir de experiencias alejadas de la clase.

En este momento de reflexión, el grupo Pandora reconoce la necesidad de no incurrir en la normalización y hegemonización de los sujetos en las prácticas matemáticas que se generan en el desarrollo de las clases; descolonizarnos a partir de la consideración de otros aprendizajes, estrategias y modos distintos a los que conocemos; el contexto; asumir la construcción social como una de las maneras de crear y recrear el conocimiento; y el entendimiento del estudiante como un sujeto que tiene potencialidades y que desde ellas puede acercarse a las matemáticas. Se encontraron experiencias similares, como la de Ordóñez (2009, 2011), quien hace una invitación a contemplar procesos en las clases de matemáticas, producto de la interacción, le da al estudiante un rol de agente investigador y de constructor de saberes, un aspecto importante en la conformación de redes y colectivos de estudiantes, además de resaltar la fortaleza de los actos comunicativos.

Con lo anterior, se espera darle continuidad al sentido investigativo con los estudiantes, de tal manera que la participación de los estudiantes en la clase aumente sustancialmente, como se pudo constatar en las experiencias antes relatadas, haciendo un reconfiguración y potenciación de las interacciones entre ellos y la participación de quienes tradicionalmente son excluidos de la clase.

Toma fuerza y puede ser motivo de investigación posterior, por ejemplo: ¿Qué queremos enseñar y qué es lo que resultamos enseñando? ¿Qué queremos que aprendan los estudiantes, qué es lo que quieren ellos 
y qué es lo que resultan aprendiendo? ¿Quién nos dice que enseñar y qué aprender y por qué es importante hacerlo o no hacerlo? Interrogantes a la espera de ser abordados.

\section{Referencias}

Bateson, G. y Bateson, M. (1989). El temor de los ángeles. Barcelona: Gedisa.

Hanson, N. (1971). Patrones de descubrimiento. Observación y explicación. Versión Española de Garcia, E. y Montesinos, A. Madrid. Alianza Editorial.

Henao, R. (2007) La razonabilidad en una didáctica de la lógica abductiva: una estrategia para la formación de maestros. [Tesis de doctorado, Universidad de Antioquia]. Repositorio institucional UdeA.

Ludlow, A. (1998). Procesos inferenciales en el pensamiento matemático de Miguel. Revista EMA, 4(1), 3-15.

Malagón, Y. (1995). Una opción de clase de matemáticas a nivel medio. Nodos y Nudos, 1(1), 30-33.

Mandelbrot, B. (2004). Fractals and chaos. Yorktown, Nueva York: Ed. Mathemathics Department Yale University.

Maturana, H. y Varela, F. (1997). De máquinas y seres vivos. Autopoiesis: la organización de lo vivo. Santiago de Chile: Editorial Universitaria.
Morin, E. (1999). Ciência com consciência. Río de Janeiro: Ed. Bertrand Brasil.

Morin, E. (2000) A cabeça bem feita: Repensar a reforma, reformar o pensamento. Río de Janeiro: Ed. Bertrand Brasil.

Morin, E. y Le Moigne, J.L. (1999). A inteligencia da complexidade., Sao Paulo: Ed. Peirópolis.

Ordóñez, L. (2009). La comunicación en clase de matemáticas. Nodos y Nudos, 3(26), 57-67.

Ordóñez, L. (2011). Matemáticas y Lenguaje. Lo que la historia ha unido, no lo separe la escuela. Nodos y Nudos, 3(30), 55-64.

Ovejero, A. y Pastor, J. (2001). La dialéctica saber/poder en Michel Foucault: un instrumento de reflexión crítica sobre la escuela. Aula Abierta, 77, 99-107. https://dialnet.unirioja.es/descarga/articulo/45498.pdf

Poincaré, H. (1890). Sur le problème des trois corps et les équations de la dynamique. Acta Math, 13, 1-270. https:// henripoincarepapers.univ-lorraine.fr/bibliohp/?a=onftar$\mathrm{t}=\mathrm{Sur}+\mathrm{le}+$ probl\%C $3 \% \mathrm{~A} 8 \mathrm{me}+\mathrm{des}+$ trois + corps $+\mathrm{e}-$ $\mathrm{t}+$ les+\%C3\%A9quations+de+la+dynamiquectaction $=g 0$

Segura, D. (1999). El conocimiento escolar el des-conocimiento escolar. Nodos y Nudos, 1(6), 4-10. 


\section{Diálogo del conocimiento}

Es recurrente encontrar muchas clases de matemáticas en las que el estudiante se aburre porque no comprende, sufre y hasta llega a desertar de toda experiencia que tenga que ver con área en su vida. Es común escuchar expresiones como: "eso es para cerebritos", "no soy bueno para matemáticas", "iEs la materia más difícil del colegio!", "si me va mal en matemáticas, me prohíben participar en otras actividades"... En ocasiones nos acostumbramos a que esta situación sea natural; al punto que quienes enseñamos matemáticas nos sentimos diferentes a los otros. ¿Es esto posible? La respuesta, asi suene fuerte, es que en muchos escenarios del mundo ocurre este fenómeno que evidencia un rechazo hacia las matemáticas por parte de muchos estudiantes. Esto, a causa de múltiples factores, que no es el propósito enumerar aquí; sin embargo, la experiencia de Pandora muestra una radiografía de la realidad que identifican en sus Instituciones, pero a la vez, un plan de acción que elaboran para cambiar esa vivencia. Ojalá se multiplicaran más colectivos como Pandora, que nos invitan a mirar en forma reflexiva y crítica nuestras prácticas docentes para determinar, entre otros aspectos, si estas responden a las necesidades de los estudiantes que tenemos a cargo, si como maestros estamos fomentando el entusiasmo y la emoción por el conocimiento, si dentro de la identidad como maestros de matemáticas estamos sembrando sueños para generaciones futuras.

Con ocasión de la experiencia reflexiva que deja este colectivo de docentes del área de matemáticas que asumen el gran reto de unirse, a pesar de estar en diferentes latitudes de la ciudad, se revela que actuando en equipo bajo el deseo y aspiración común de transformar las prácticas de hacer matemáticas en la Escuela. Se pueden lograr cambios puntuales en los ambientes de clase desde el cambio de actitudes, emociones y el rendimiento de los estudiantes.

Pandora le apuesta a hacer rupturas en los ambientes de la clase tradicional de matemáticas, de tal modo, que se rompen los hilos de poder en el aula. Se prohíbe la discriminación entre los buenos y malos en matemáticas, en la enseñanza no prima tanto el contenido matemático como punto de partida, sino que este emerge luego de abordar preguntas o situaciones problema en su mayoría sencillas, pero desafiantes e inesperadas para el estudiante. El ambiente de clase con esta dinámica invita a que se pase a escuchar las voces de los estudiantes, se dé la posibilidad de cometer errores y aprender de ellos, se rompan las rutinas de cumplir con currículos estrictos alejados de los intereses y contextos de los estudiantes, gestionando actividades para encontrar y construir verdaderos significados de la matemática, sus diferentes matices y su carácter interdisciplinar que le da sentido al mundo que vivimos. 


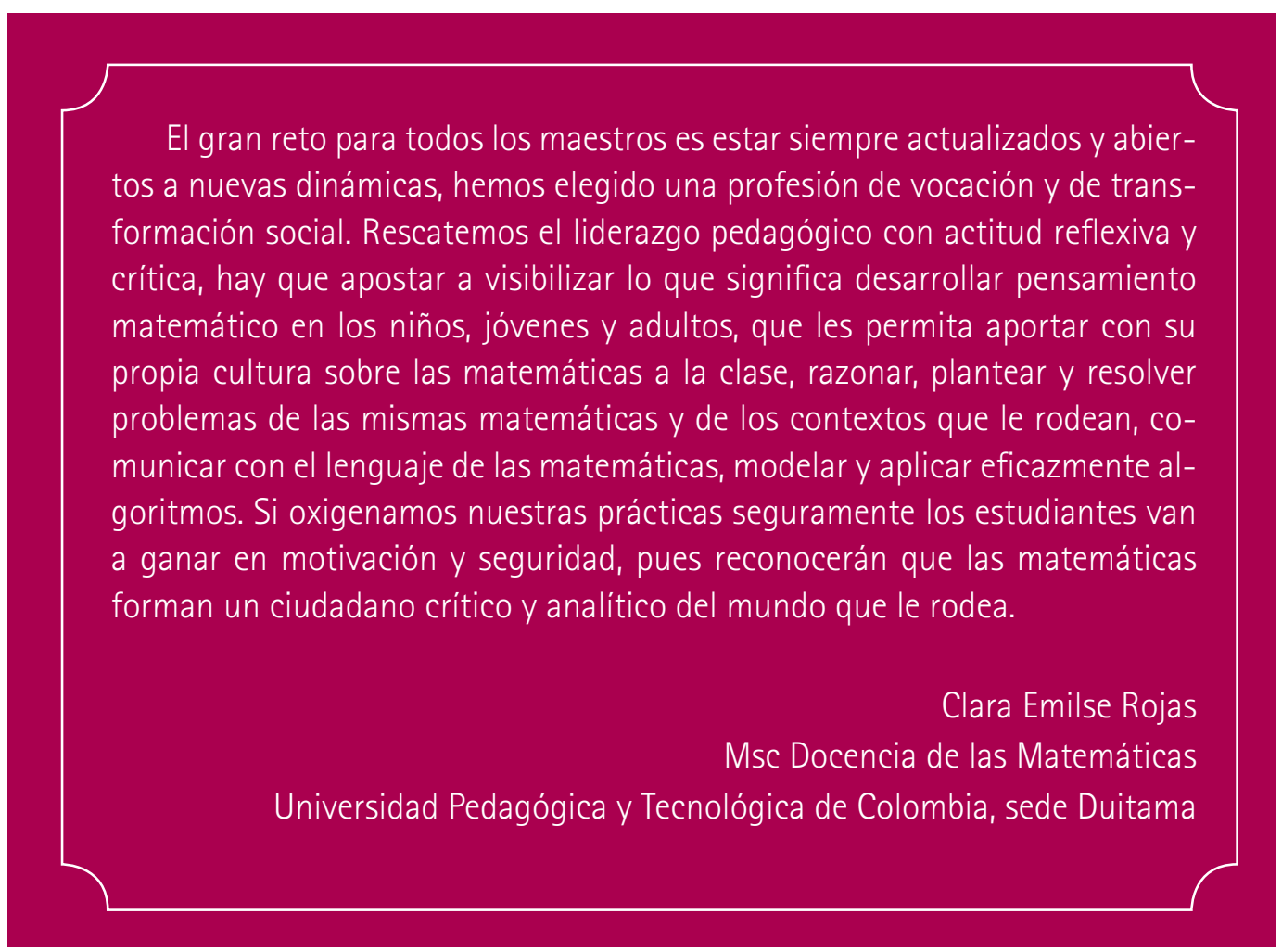

